\title{
Pensononowoor
}

2017 , vol. $77,59-64$

http://dx.doi.org/10.12657/denbio.077.005

\author{
Weronika B. Żukowska*, Błażej Wójkiewicz*, Monika Litkowiec, \\ Witold Wachowiak
}

\section{Cross-amplification and multiplexing of cpSSRs and nSSRs in two closely related pine species (Pinus sylvestris L. and P. mugo Turra)}

Received: 14 April 2016; Accepted: 16 November 2016

\begin{abstract}
Background: Simple sequence repeats (SSRs) are widespread molecular markers commonly used in population genetic studies. Nowadays, next-generation sequencing (NGS) methods allow identifying thousands of SSRs in one sequencing run, which greatly facilitates isolation and development of new SSRs. However, their usefulness as molecular markers still must be tested empirically on a number of populations to select SSRs with best parameters for future population genetic research. An alternative approach, cheaper and faster than isolation and characterization of new SSRs, involves cross-amplification of SSRs in closely related species. Aims: Our goal was to develop multiplex PCR protocols that will be useful in population genetic studies of Scots pine (Pinus sylvestris L.) and dwarf mountain pine (P. mugo Turra), and possibly other pine species. Methods: We tested 14 chloroplast (cpSSRs) and 22 nuclear (nSSRs) microsatellite markers originally designed for Japanese black pine (P. thunbergii Parl.), P. sylvestris and loblolly pine (P. taeda L.) in four populations of $P$. sylvestris and $P$. mugo across different locations in Europe. We designed six multiplex PCRs, which were subsequently screened for their ability to provide repeatable and high quality amplification products using capillary electrophoresis.

Results: The transfer rate in our study was similar in both pine species, and it was very high for cpSSRs (93\% and $86 \%$ for P. sylvestris and P. mugo, respectively) and moderate for nSSRs (59\% for both species). We managed to design five well-performing multiplex reactions out of six initially tested. Most of the tested loci were polymorphic. Moreover, the allelic patterns detected at some cpSSRs were species-specific.

Conclusions: We provide a set of five multiplexes which can be used in genetic studies of both $P$. sylvestris and P. mugo. Chloroplast marker PCP30277 is a good candidate for a cheap species diagnostic marker suitable for tracking interspecific gene flow between hybridizing species of $P$. sylvestris and $P$. mugo.
\end{abstract}

Keywords: chloroplast microsatellites, dwarf mountain pine, hybridization, nuclear microsatellites, Scots pine

Addresses: W. B. Żukowska, Institute of Dendrology, Polish Academy of Sciences, Parkowa 5, 62-035 Kórnik, Poland, e-mail: wzukowska@man.poznan.pl

B. Wójkiewicz, Institute of Dendrology, Polish Academy of Sciences, Parkowa 5, 62-035 Kórnik, Poland, e-mail: bwojkiew@man.poznan.pl

M. Litkowiec, Institute of Dendrology, Polish Academy of Sciences, Parkowa 5, 62-035 Kórnik, Poland, e-mail: mlit@man.poznan.pl

W. Wachowiak, Institute of Environmental Biology, Faculty of Biology, Adam Mickiewicz University, Umultowska 89, 61-614 Poznań, Poland; Institute of Dendrology, Polish Academy of Sciences, Parkowa 5 , 62-035 Kórnik, Poland, e-mail: witwac@amu.edu.pl

* - W.B. Żukowska and B. Wójkiewicz contributed equally to this work. 


\section{Introduction}

Microsatellites (=simple sequence repeats; SSRs or short tandem repeats; STRs) are the class of repetitive DNA sequences present in both eukaryotic and prokaryotic genomes. With respect to population genetics of forest tree species, microsatellites have proved to be useful neutral molecular markers in studies focusing on genetic diversity (e.g. Chybicki et al., 2011; Litkowiec et al., 2015; Wójkiewicz \& Wachowiak, 2016), mating systems (e.g. Lian et al., 2001) and gene mapping (e.g. Echt et al., 2011) due to their high level of allelic variation and co-dominant mode of inheritance. The popularity of SSRs in genetic research of trees is also connected with the fact that they can be genotyped in one multiplex polymerase chain reaction (PCR). This technique allows amplification of two or more DNA fragments simultaneously. The possibility of multiplexing combined with capillary electrophoresis, which is based on a laser-induced fluorescence DNA technology, results in a cost-effective tool for genotyping large quantities of independent samples.

Till the next-generation sequencing (NGS) era, the development of novel microsatellite markers for forest tree species was difficult, costly and time-consuming. Currently, it is possible to identify thousands of microsatellite regions during one sequencing run of a genome or transcriptome. As a result, the isolation of new SSRs is no longer a real challenge, practically for any organism, including trees. Regardless of this, the usefulness of novel SSRs for population genetic studies still must be tested to verify which of them 1) provide repeatable, polymorphic and high quality amplification products, 2) are the most informative and 3) are transferable, which gives opportunity to perform genetic analyses at interspecific level.

The objects of our study were two very closely related pine species: Scots pine (Pinus sylvestris L.) and dwarf mountain pine (P. mugo Turra). At present these species have mostly allopatric distribution. $P$. sylvestris is the most widespread conifer in Europe and Asia, whereas P. mugo is typical to the mountain regions of Europe. We aimed at developing of efficient multiplex protocols for the amplification of chloroplast and nuclear SSRs (cpSSRs and nSSRs, respectively) in P. sylvestris and P. mugo, which we had pre-selected from a collection of 36 SSRs originally designed for $P$. thunbergii Parl., P. sylvestris and P. taeda L. (Table 1). The results of the cross-species amplification of cpSSRs and nSSRs are discussed in the light of their utility for future genetic research.

\section{Methods}

Four populations of $P$. sylvestris (128 individuals) and four populations of $P$. mugo (105 individuals) across different locations in Europe were analysed in this study (Table 2). The collected samples were stored in $-20^{\circ} \mathrm{C}$ until DNA extraction. Genomic DNA was extracted from 50-100 mg of needle tissue, following the CTAB protocol as described by Dumolin et al. (1995). RNase A was added to the final incubation step. The DNA concentration was measured with BioPhotometer (Eppendorf AG, Germany) and adjusted to $15 \mathrm{ng} / \mu \mathrm{l}$.

We selected 14 chloroplast and 22 nuclear microsatellite markers available in the published literature (Table 1). CpSSRs were initially developed for P. thunbergii, whereas nSSRs for $P$. sylvestris and P. taeda. The markers were combined into six multiplex PCRs and screened for their ability to provide repeatable and high quality polymorphic amplification products of expected size. The loci were finally amplified in five multiplex PCRs in Applied Biosystems Veriti and 2720 thermal cyclers (Life Technologies, USA). The PCRs were carried out in a total volume of $10 \mu \mathrm{l}$, using the Qiagen Multiplex PCR kit (Qiagen, Germany). Each reaction contained about $45 \mathrm{ng}$ of template DNA, 1x Qiagen Multiplex PCR Master Mix, 0.5x Q-Solution and 0.05-0.1 $\mu \mathrm{M}$ each of forward and reverse primers. All primers were tested individually prior to the performance of multiplex reactions. We used equimolar concentration of primers in the initial amplification procedures, which were subsequently adjusted to obtain an even intensity of the fluorescence signal. Amplification conditions were optimised across all multiplexes for both pine species. Details of final PCR parameters are described in Table 1. The fluorescently labelled PCR products were separated on a capillary sequencer, the Applied Biosystems 3130 Genetic Analyzer (Life Technologies, USA). The GeneScan 500 LIZ Size Standard (Life Technologies, USA) was used as an internal size standard. The raw data were scored with the GeneMapper Software ver 4.0 (Life Technologies, USA), checked manually and converted into discrete allele sizes with the use of the AlleloBin software (Prasanth et al., 2006).

Two parameters were calculated for each species for cpSSRs: the number of alleles $\left(\mathrm{A}_{N}\right)$ and unbiased diversity $\left(A_{u h}\right)$ using GenAlEx ver 6.5 (Peakall \& Smouse, 2006). $A_{u h}$ was computed as mean across all populations for each species. With regard to nSSRs, we used the multiple sample score test (U test for heterozygote deficit, Raymond and Rousset 1995), implemented in GENEPOP ver 4.3 (Rousset, 2008), to assess the significance of departures from Hardy-Weinberg equilibrium (HWE) for each locus, separately for each species. The frequency of null alleles (NAF) was estimated using FreeNA (Chapuis \& Estoup, 2007) separately for each population and each species. $A_{N}$, effective number of alleles $\left(A_{E}\right)$, observed and expected heterozygosity $\left(\mathrm{H}_{\mathrm{O}}\right.$ and $\mathrm{H}_{\mathrm{E}}$, 
Table 1. A list of multiplexes and thermocycling conditions for P. sylvestris and P. mugo. Multiplex 4 (nSSR) is omitted as the loci (psyl17 (Sebastiani et al., 2012), ptTX3116 (Elsik \& Williams, 2001), SPAC11.6, SPAC 11.8, SPAC 12.5 (Soranzo et al., 1998) failed to amplify in both P. sylvestris and P. mugo. Each reaction consisted of the following steps: I - initial denaturation, II - denaturation, III - annealing, IV - elongation, V - final elongation

\begin{tabular}{|c|c|c|c|c|}
\hline Multiplex & Loci & Step & P. sylvestris & P. mugo \\
\hline \multirow{5}{*}{1 (cpSSR) } & \multirow{5}{*}{$\begin{array}{l}\text { Pt15169, Pt26081, } \\
\text { Pt30204, Pt36480, } \\
\text { Pt45002, Pt71936 (Vendra- } \\
\text { min et al., 1996) }\end{array}$} & I & $95^{\circ} \mathrm{C}, 15 \mathrm{~min}$. & $95^{\circ} \mathrm{C}, 15 \mathrm{~min}$. \\
\hline & & II & $94^{\circ} \mathrm{C}, 15 \mathrm{sec}$ & $94^{\circ} \mathrm{C}, 30 \mathrm{sec}$ \\
\hline & & III & $58^{\circ} \mathrm{C}, 90 \mathrm{sec}$ & $58^{\circ} \mathrm{C}, 45 \mathrm{sec}$ \\
\hline & & IV & $72^{\circ} \mathrm{C}, 90$ sec.; go to II $\times 27$ & $72^{\circ} \mathrm{C}, 90$ sec.; go to II $\times 30$ \\
\hline & & $\mathrm{V}$ & $72^{\circ} \mathrm{C}, 10 \mathrm{~min}$ & $72^{\circ} \mathrm{C}, 10 \mathrm{~min}$ \\
\hline \multirow{5}{*}{2 (cpSSR) } & \multirow{5}{*}{$\begin{array}{l}\text { PCP1289, PCP26106, } \\
\text { PCP30277, PCP36567, } \\
\text { PCP41131, PCP45071, } \\
\text { PCP87314, PCP102652 } \\
\text { (Provan et al., 1998) }\end{array}$} & I & $95^{\circ} \mathrm{C}, 15 \mathrm{~min}$. & $95^{\circ} \mathrm{C}, 15 \mathrm{~min}$. \\
\hline & & II & $94^{\circ} \mathrm{C}, 15 \mathrm{sec}$ & $94^{\circ} \mathrm{C}, 30 \mathrm{sec}$ \\
\hline & & III & $60^{\circ} \mathrm{C}, 90 \mathrm{sec}$ & $60^{\circ} \mathrm{C}, 45 \mathrm{sec}$ \\
\hline & & IV & $72^{\circ} \mathrm{C}, 90$ sec.; go to II $\times 27$ & $72^{\circ} \mathrm{C}, 90$ sec.; go to II $\times 30$ \\
\hline & & $\mathrm{V}$ & $72^{\circ} \mathrm{C}, 10 \mathrm{~min}$ & $72^{\circ} \mathrm{C}, 10 \mathrm{~min}$ \\
\hline \multirow{5}{*}{3 (nSSR) } & \multirow{5}{*}{$\begin{array}{l}\text { psyl2, psyl16, psyl18, } \\
\text { psyl19, psyl25, psyl36, } \\
\text { psyl42, psyl44, psyl57 } \\
\text { (Sebastiani et al., 2012) }\end{array}$} & I & $95^{\circ} \mathrm{C}, 15 \mathrm{~min}$ & $95^{\circ} \mathrm{C}, 15 \mathrm{~min}$. \\
\hline & & II & $94^{\circ} \mathrm{C}, 30 \mathrm{sec}$ & $94^{\circ} \mathrm{C}, 30 \mathrm{sec}$ \\
\hline & & III & $57^{\circ} \mathrm{C}, 90 \mathrm{sec}$ & $55^{\circ} \mathrm{C}, 90 \mathrm{sec}$ \\
\hline & & IV & $72^{\circ} \mathrm{C}, 90$ sec.; go to $\mathrm{II} \times 37$ & $72^{\circ} \mathrm{C}, 90$ sec.; go to $\mathrm{II} \times 37$ \\
\hline & & $\mathrm{V}$ & $72^{\circ} \mathrm{C}, 10 \mathrm{~min}$ & $72^{\circ} \mathrm{C}, 15 \mathrm{~min}$ \\
\hline \multirow{5}{*}{5 (nSSR) } & \multirow{5}{*}{$\begin{array}{l}\text { ptTX2146 (Elsik et al., } \\
\text { 2000), } \\
\text { ptTX3107 (Elsik \& Wil- } \\
\text { liams, 2001), } \\
\text { SPAG } 7.14 \text { (Soranzo et al., } \\
\text { 1998) }\end{array}$} & I & $95^{\circ} \mathrm{C}, 15 \mathrm{~min}$. & $95^{\circ} \mathrm{C}, 15 \mathrm{~min}$. \\
\hline & & II & $94^{\circ} \mathrm{C}, 30 \mathrm{sec}$ & $94^{\circ} \mathrm{C}, 30 \mathrm{sec}$ \\
\hline & & III & $55^{\circ} \mathrm{C}, 90 \mathrm{sec}$ & $56^{\circ} \mathrm{C}, 90 \mathrm{sec}$ \\
\hline & & IV & $72^{\circ} \mathrm{C}, 90$ sec.; go to II $\times 29$ & $72^{\circ} \mathrm{C}, 90$ sec.; go to II $\times 34$ \\
\hline & & $\mathrm{V}$ & $72^{\circ} \mathrm{C}, 10 \mathrm{~min}$ & $72^{\circ} \mathrm{C}, 15 \mathrm{~min}$ \\
\hline \multirow{8}{*}{6 (nSSR) } & \multirow{8}{*}{$\begin{array}{l}\text { ptTX3025, ptTX3032 (El- } \\
\text { sik et al., 2000), ptTX4001, } \\
\text { ptTX4011 (Zhou et al., } \\
\text { 2002), SPAC } 11.4 \\
\text { (Soranzo et al., 1998) }\end{array}$} & $\mathrm{I}$ & $95^{\circ} \mathrm{C}, 15 \mathrm{~min}$. & $95^{\circ} \mathrm{C}, 15 \mathrm{~min}$ \\
\hline & & II-1 & $94^{\circ} \mathrm{C}, 30 \mathrm{sec}$ & $94^{\circ} \mathrm{C}, 30 \mathrm{sec}$ \\
\hline & & III-1 & $60^{\circ} \mathrm{C} \Delta \downarrow 1^{\circ} \mathrm{C} /$ cycle, $40 \mathrm{sec}$. & $65^{\circ} \mathrm{C} \Delta \downarrow 1^{\circ} \mathrm{C} /$ cycle, $40 \mathrm{sec}$. \\
\hline & & IV-1 & $72^{\circ} \mathrm{C}, 90$ sec.; go to II- $1 \times 9$ & $72^{\circ} \mathrm{C}, 60$ sec.; go to II- $1 \times 9$ \\
\hline & & II-2 & $94^{\circ} \mathrm{C}, 30 \mathrm{sec}$ & $94^{\circ} \mathrm{C}, 30 \mathrm{sec}$ \\
\hline & & III-2 & $50^{\circ} \mathrm{C}, 40 \mathrm{sec}$ & $55^{\circ} \mathrm{C}, 60 \mathrm{sec}$ \\
\hline & & IV-2 & $72^{\circ} \mathrm{C}, 90$ sec.; go to II- $2 \times 35$ & $72^{\circ} \mathrm{C}, 60$ sec.; go to II- $2 \times 31$ \\
\hline & & $\mathrm{V}$ & $72^{\circ} \mathrm{C}, 10 \mathrm{~min}$ & $72^{\circ} \mathrm{C}, 7 \mathrm{~min}$. \\
\hline
\end{tabular}

respectively) were calculated in GenAlEx ver 6.5 across all populations separately for each species.

\section{Results \& Discussion}

The transfer rates were very similar in both $P$. sylvestris and P. mugo. We managed to transfer 13 (93\%) and $12(86 \%)$ out of 14 initially tested chloroplast microsatellites to $P$. sylvestris and $P$. mugo, respectively. Locus Pt36480 was successfully transferred only to $P$. sylvestris. Similar high values of transfer rates for cPSSRs were noted previously by Dzialuk and Burczyk (2004), who proposed a multiplex PCR that consisted of six loci for population studies in $P$. sylvestris. With regard to nuclear microsatellites, the transfer rates were moderate $(59 \%)$ for both pines. Similarly to our results, moderately low (26\%) transfer rates were demonstrated by Celiński et al. (2013), who tested the transferability of 19 nSSRs from $P$. sylvestris and $P$. taeda to P. mugo. In our study, 13 out of $22 \mathrm{nSSRs}$ were amplified successfully in both species, but some loci that failed to amplify or gave poor results in $P$. sylvestris turned out to be useful for $P$. mugo and vice-versa (ptTX3107 and SPAC 11.4 only for P. sylvestris, whereas psyl16 and ptTX4001 only for $P$. mugo). Our results clearly show that the amplification of cpSSRs was more successful than nSSRs, which is most likely associated with the fact that the mutation rate of chloroplast DNA is lower than of nuclear DNA (Willyard et al., 2007). As a result, the high sequence conservation among chloroplast genomes of conifers allows successful amplification of cpSSRs designed for $P$. thunbergii in closely (as in our study) or more distantly related conifer species.

Allelic variation of the analysed loci was high with mean 7.12 and 6.32 alleles per locus for $P$. sylvestris and P. mugo, respectively. Nearly all successfully amplified 
Table 2. Descriptive statistics of the studied cpSSR and nSSR markers in P. sylvestris (S) and P. mugo (M) ${ }^{*}$. $\mathrm{A}_{\mathrm{N}}-$ number of alleles; $\mathrm{A}_{\mathrm{uh}}$ - unbiased diversity (mean for all populations); $\mathrm{A}_{\mathrm{E}}$ - effective number of alleles; $\mathrm{H}_{\mathrm{O}}$ - observed heterozygosity; $\mathrm{H}_{\mathrm{E}}$ - expected heterozygosity; NAF - null allele frequency (range for all populations). Test for heterozygote deficit: ns - not significant; ${ }^{*}-\mathrm{p}<0.05 ;{ }^{* *}-\mathrm{p}<0.01 ;^{* * *}-\mathrm{p}<0.001$

\begin{tabular}{|c|c|c|c|c|c|c|c|}
\hline \multirow{2}{*}{ Locus } & Size range $[b p]$ & $A_{N}$ & $A_{\text {uh }}$ & $A_{E}$ & $\mathrm{H}_{\mathrm{O}}$ & $\mathrm{H}_{\mathrm{E}}$ & NAF \\
\hline & $\mathrm{S} / \mathrm{M}$ & $\mathrm{S} / \mathrm{M}$ & $\mathrm{S} / \mathrm{M}$ & $\mathrm{S} / \mathrm{M}$ & $\mathrm{S} / \mathrm{M}$ & $\mathrm{S} / \mathrm{M}$ & $\mathrm{S} / \mathrm{M}$ \\
\hline Pt15169 & $124-130 / 121-126$ & $7 / 5$ & $0.75 / 0.56$ & $-/-$ & $-/-$ & $-/-$ & $-/-$ \\
\hline Pt26081 & 110-112/109-112 & $3 / 4$ & $0.26 / 0.48$ & $-/-$ & $-/-$ & $-/-$ & $-/-$ \\
\hline Pt30204 & $140-148 / 143-149$ & $9 / 7$ & $0.79 / 0.79$ & $-/-$ & $-/-$ & $-/-$ & $-/-$ \\
\hline Pt36480 & $143-145 /-$ & $3 /-$ & $0.18 /-$ & $-/-$ & $-/-$ & $-/-$ & $-/-$ \\
\hline Pt71936 & $148-154 / 145-149$ & $7 / 5$ & $0.64 / 0.62$ & $-/-$ & $-1-$ & $-1-$ & $-/-$ \\
\hline PCP1289 & $108-111 / 107-108$ & $4 / 2$ & $0.35 / 0.17$ & $-1-$ & $-1-$ & $-1-$ & $-1-$ \\
\hline РCP26106 & $146-148 / 145-148$ & $3 / 4$ & $0.28 / 0.50$ & $-/-$ & $-1-$ & $-1-$ & $-1-$ \\
\hline РCP30277 & $134-140 / 115-120$ & $7 / 6$ & $0.77 / 0.75$ & $-/-$ & $-/-$ & $-1-$ & $-1-$ \\
\hline PCP36567 & $110-112 / 110-112$ & $3 / 3$ & $0.12 / 0.47$ & $-1-$ & $-1-$ & $-1-$ & $-1-$ \\
\hline PCP41131 & 139-143/140-159 & $5 / 10$ & $0.16 / 0.69$ & $-/-$ & $-/-$ & $-/-$ & $-/-$ \\
\hline РCP45071 & $153-156 / 146-151$ & $4 / 6$ & $0.45 / 0.55$ & $-1-$ & $-/-$ & $-/-$ & $-/-$ \\
\hline РCP87314 & $112-114 / 112-116$ & $3 / 5$ & $0.32 / 0.68$ & $-/-$ & $-/-$ & $-1-$ & $-/-$ \\
\hline PCP102652 & $114-116 / 114$ & $3 / 1$ & $0.03 / 0.00$ & $-/-$ & $-/-$ & $-/-$ & $-/-$ \\
\hline psyl2 & $207-213 / 198-210$ & $3 / 5$ & $-/-$ & $1.29 / 1.54$ & $0.21 / 0.32$ & $0.22 / 0.34$ & $\begin{array}{l}0.00-0.13^{\mathrm{ns}} / \\
0.00-0.13^{\mathrm{ns}}\end{array}$ \\
\hline psyl16 & $-/ 201-213$ & $-/ 6$ & $-/-$ & $-/ 3.03$ & $-/ 0.64$ & $-/ 0.67$ & $-/ 0.00-0.06^{\mathrm{ns}}$ \\
\hline psyl18 & $292-307 / 292-304$ & $6 / 5$ & $-/-$ & $1.28 / 1.18$ & $0.16 / 0.12$ & $0.21 / 0.15$ & $\begin{array}{l}0.00-0.08^{*} / \\
0.00-0.12^{* *}\end{array}$ \\
\hline psyl25 & $216-219 / 213-219$ & $2 / 3$ & $-/-$ & $1.02 / 1.57$ & $0.02 / 0.38$ & $0.02 / 0.36$ & $\begin{array}{l}0.00^{\mathrm{ns}} / \\
0.00-0.03^{\mathrm{ns}}\end{array}$ \\
\hline psyl36 & $250-262 / 250-262$ & $5 / 5$ & $-/-$ & $1.27 / 1.12$ & $0.22 / 0.07$ & $0.21 / 0.10$ & $\begin{array}{l}0.00^{\mathrm{ns}} / \\
0.00-0.13^{* *}\end{array}$ \\
\hline psyl42 & 167-179/169-177 & $7 / 4$ & $-/-$ & $3.25 / 2.10$ & $0.69 / 0.51$ & $0.69 / 0.50$ & $\begin{array}{l}0.00-0.03^{\mathrm{ns}} / \\
0.00-0.05^{\mathrm{ns}}\end{array}$ \\
\hline psyl44 & 169-178/169-175 & $4 / 2$ & $-/-$ & $1.19 / 1.29$ & $0.15 / 0.26$ & $0.16 / 0.22$ & $\begin{array}{l}0.00-0.06^{\mathrm{ns}} / \\
0.00^{\mathrm{ns}}\end{array}$ \\
\hline psyl57 & 190-208/190-205 & $7 / 6$ & $-/-$ & $2.35 / 2.63$ & $0.62 / 0.62$ & $0.57 / 0.61$ & $\begin{array}{l}0.00-0.02^{\mathrm{ns}} / \\
0.00-0.09^{\mathrm{ns}}\end{array}$ \\
\hline ptTX2146 & $180-252 / 153-264$ & $17 / 17$ & $-/-$ & $3.86 / 3.24$ & $0.74 / 0.64$ & $0.74 / 0.63$ & $\begin{array}{l}0.00-0.04^{\mathrm{ns}} / \\
0.00-0.01^{\mathrm{ns}}\end{array}$ \\
\hline ptTX3107 & $153-183 /-$ & $8 /-$ & $-/-$ & $4.39 /-$ & $0.44 /-$ & $0.77 /-$ & $0.15-0.26^{* * *} /-$ \\
\hline SPAG 7.14 & $177-257 / 185-265$ & $30 / 28$ & $-/-$ & $14.29 / 11.56$ & $0.77 / 0.80$ & $0.93 / 0.91$ & $\begin{array}{l}0.00-0.14^{* * *} / \\
0.00-0.15^{* * *}\end{array}$ \\
\hline ptTX3025 & $266-299 / 266-275$ & $7 / 4$ & $-/-$ & $1.90 / 1.27$ & $0.43 / 0.19$ & $0.47 / 0.21$ & $\begin{array}{l}0.00-0.12^{*} / \\
0.00-0.11^{*}\end{array}$ \\
\hline ptTX4001 & $-/ 205-221$ & $-/ 6$ & $-/-$ & $-/ 2.66$ & $-/ 0.53$ & $-/ 0.58$ & $-/ 0.00-0.05^{\mathrm{ns}}$ \\
\hline ptTX4011 & $256-280 / 262-284$ & $10 / 9$ & $-/-$ & $3.10 / 3.27$ & $0.62 / 0.60$ & $0.68 / 0.67$ & $\begin{array}{l}0.00-0.15^{* *} / \\
0.00-0.18^{* *}\end{array}$ \\
\hline SPAC 11.4 & $130-166 /-$ & $18 /-$ & $-/-$ & $7.10 /-$ & $0.88 /-$ & $0.85 /-$ & $0.00-0.02^{\mathrm{ns}} /-$ \\
\hline Mean & & $7.12 / 6.32$ & $0.39 / 0.52$ & $3.56 / 2.80$ & $0.46 / 0.44$ & $0.50 / 0.46$ & $0.04 / 0.03$ \\
\hline
\end{tabular}

*Populations analysed in the study (long./lat.):

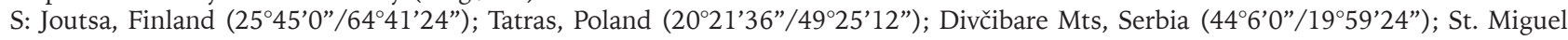
d'Engolasters, Andorra (4240'12"/0 $\left.46^{\prime} 12^{\prime \prime}\right)$.

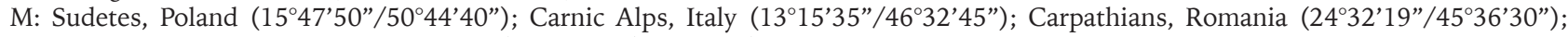
Dinaric Alps, Bosnia and Herzegovina (18 $\left.13^{\prime} 08^{\prime \prime} / 43^{\circ} 45^{\prime} 00^{\prime \prime}\right)$.

cPSSRs were polymorphic, exhibiting between two to ten alleles. Only PCP102652 was monomorphic in $P$. mugo (114 bp), whereas almost all individuals of $P$. sylvestris (99\%) carried the 115 bp variant. In the case of nSSRs, $A_{N}$ was lower for markers developed by Sebastiani et al. (2012) (the 'psyl' series; $A_{N}$ between two and seven) than for other nSSRs (from four for ptTX3025 in P. mugo up to 30 for SPAG 7.14 in $P$. sylvestris). The mean value of unbiased diversity (mean $\mathrm{A}_{\mathrm{uh}}$ ) parameter, calculated for cpSSRs, did not differ statistically between the studied pines (mean $\mathrm{A}_{\mathrm{uh}}=0.39$ and mean $\mathrm{A}_{\mathrm{uh}}=0.52$ for P. sylvestris and P. mugo, respectively; Student's t-test: $\mathrm{p}=0.20$ ). As for nSSRs, the difference between the mean effective number of alleles $\left(A_{E}\right)$ was also not significant (3.56 for P. sylvestris vs. 2.80 for P. mugo; U Mann-Whitney 
test: $p=0.63)$. Significant heterozygote deficit was observed for six loci (psyl18, psyl36, ptTX3107, SPAG 7.14, ptTX3025, and ptTX4011). The frequency of null alleles (NAF) differed across loci and, to a lesser extent, between species (NAF $=0.00-0.26)$. The mean observed and expected heterozygosity $\left(\mathrm{H}_{\mathrm{O}}\right.$ and $\mathrm{H}_{\mathrm{E}}$, respectively) were similar in both species (mean $\mathrm{H}_{\mathrm{O}}=0.46$, mean $\mathrm{H}_{\mathrm{E}}=0.50$ and mean $\mathrm{H}_{\mathrm{O}}=$ 0.44 , mean $\mathrm{H}_{\mathrm{E}}=0.46$ for $P$. sylvestris and $P$. mugo, respectively; Student's t-test: $\mathrm{p}=0.84$ for $\mathrm{H}_{\mathrm{O}}$ and $\mathrm{p}=$ 0.69 for $\mathrm{H}_{\mathrm{E}}$ ). For most loci $\mathrm{H}_{\mathrm{O}}$ was only slightly lower than $\mathrm{H}_{\mathrm{E}}$. Some loci, however, displayed $\mathrm{H}_{\mathrm{O}}$ greater than $\mathrm{H}_{\mathrm{E}}$. Microsatellites with higher number of repeats generally displayed higher heterozygosity values (Table 2). Based on our results, we recommend to omit some nSSR loci with the frequency of null alleles exceeding 5\%, including psyl18, ptTX3107, SPAG 7.14, and ptTX4011. Alternatively, a proper correction methods should be applied as, according to the simulation study by Chapuis and Estoup (2007), the levels of classical parameters used to describe population differentiation are overestimated in the presence of null alleles.

Loci that exhibit species-specific allelic patterns are ideal for studies of interspecific gene flow and identification of hybrid zones. In the present work, the most pronounced differences were apparent for 2 cpSSRs: PCP45071 and PCP30277. Alleles scored for these loci did not overlap when the two species were taken into account. Only 2 bp difference was observed for PCP45071 and it does not seem to be a species-specific polymorphism as compared to other studies (Wójkiewicz \& Wachowiak, 2016). The difference for PCP30277 was at least 14 bp (Table 2), and this locus can be useful as a diagnostic marker to track interspecific gene flow in the species' contact zones. Regarding interspecific differences for nSSRs, we observed opposing tendencies for psyl2 and SPAG 7.14. Higher variants in $P$. sylvestris as compared to $P$. mugo were identified for psyl2, whereas lower sizes were typical for SPAG 7.14. Variants scored for $P$. mugo represented a subset of those identified in P. sylvestris for four loci: psyl42, psyl44, psyl57, and ptTX3025. For these markers, longer alleles, preferred in $P$. sylvestris, were absent in $P$. mugo. The same $\mathrm{A}_{\mathrm{N}}$ was observed for ptTX2146 for both $P$. sylvestris and $P$. mugo, but some individuals of $P$. mugo had alleles shorter and others longer than P. sylvestris. As oppose to cpSSRs, there was no locus which had non-overlapping alleles when compared in both pine species (Table 2).

\section{Conclusions}

We provide five well-performing multiplexes consisting of sets of chloroplast and nuclear microsatellites that can be applied in population and conservation genetic studies of both $P$. sylvestris and P. mugo, and possibly of other pine species, e.g. from the $P$. mugo complex. The markers seem particularly useful for the assessment of the background neutral genetic variation that is necessary to further look for genetic signatures of natural selection in candidate genomic regions. Due to their high genetic variability, they could also be applied in the identification and tracking of plant material. Furthermore, the marker that exhibits species-specific allelic patterns (PCP30277) seems ideal for studies of interspecific gene flow in the species' contact zones. Such studies accompanied by analyses of sequence variation at candidate genomic regions will help to address questions related to the role of hybridization in evolution of P. sylvestris and P. mugo (Wachowiak et al., 2015, 2016). Our study clearly confirms that cross-amplification seems to be a good first choice alternative to the de novo development of microsatellite markers, especially for species with poor genomic resources. The possibility of genotyping using multiplex PCRs makes their application additionally time and cost-effective.

\section{Acknowledgments}

This work was financially supported by the Polish National Science Centre (Grant No. DEC2012/05/E/NZ9/03476), and the Institute of Dendrology of the Polish Academy of Sciences provided additional funding.

\section{References}

Celiński K, Pawlaczyk EM, Wojnicka-Półtorak A, Chudzińska E \& Prus-Głowacki W (2013) Cross-species amplification and characterization of microsatellite loci in Pinus mugo Turra. Biologia 68: 621-626. doi:10.2478/s11756-013-0189-z.

Chapuis MP \& Estoup A (2007) Microsatellite null alleles and estimation of population differentiation. Molecular Biology and Evolution 24: 621631. doi:10.1093/molbev/msl191.

Chybicki IJ, Oleksa A \& Burczyk J (2011) Increased inbreeding and strong kinship structure in Taxus baccata estimated from both AFLP and SSR data. Heredity 107: 589-600. doi:10.1038/hdy.2011.51.

Dumolin S, Demesure B \& Petit RJ (1995) Inheritance of chloroplast and mitochondrial genomes in pedunculate oak investigated with an efficient PCR method. Theoretical and Applied Genetics 91: 1253-1256. doi:10.1007/BF00220937.

Dzialuk A \& Burczyk J (2004) PCR-multiplex of six chloroplast microsatellites for population studies 
and genetic typing in Pinus sylvestris. Silvae Genetica 53: 246-248.

Echt CS, Saha S, Krutovsky KV, Wimalanathan K, Erpelding JE, Liang C \& Nelson CD (2011) An annotated genetic map of loblolly pine based on microsatellite and cDNA markers. BMC Genetics 12: 17. doi:10.1186/1471-2156-12-17.

Elsik CG, Minihan VT, Hall SE, Scarpa AM \& Williams CG (2000) Low-copy microsatellite markers for Pinus taeda L. Genome 43: 550-555. doi:10.1139/g00-002.

Elsik CG \& Williams CG (2001) Low-copy microsatellite recovery from a conifer genome. Theoretical and Applied Genetics 103: 1189-1195. doi:10.1007/s001220100725.

Lian C, Miwa M \& Hogetsu T (2001) Outcrossing and paternity analysis of Pinus densiflora (Japanese red pine) by microsatellite polymorphism. Heredity 87: 88-98. doi:10.1046/j.13652540.2001.00913.x.

Litkowiec M, Plitta-Michalak BP, Lewandowski A \& Iszkuło G (2015) Homogenous genetic structure in populations of Taxus baccata with varied proportions of male and female individuals. Silva Fennica 49. doi:10.14214/sf.1236.

Peakall R \& Smouse PE (2006) GENALEX 6: genetic analysis in Excel. Population genetic software for teaching and research. Molecular Ecology Notes 6: 288-295. doi:10.1111/j.14718286.2005.01155.x.

Prasanth VP, Chandra S, Hoisington DA \& Jayashree B (2006) AlleloBin - A program for allel binning of microsatellite markers based on the algorithm of Idury and Cardon (1997). ICRISAT. International Crops Research Institute for the Semi-Arid Tropics. doi:10.13140/2.1.4397.2165.

Provan J, Soranzo N, Wilson NJ, McNicol JW, Forrest GI, Cottrell J \& Powell W (1998) Gene-pool variation in Caledonian and European Scots pine (Pinus sylvestris L.) revealed by chloroplast simple-sequence repeats. Proceedings of the Royal Society B: Biological Sciences 265: 1697-1705. doi:10.1098/rspb.1998.0491.
Raymond M \& Rousset F (1995) An exact test for population differentiation. Evolution 49: 12801283. doi:10.2307/2410454.

Rousset F (2008) Genepop'007: a complete re-implementation of the genepop software for Windows and Linux. Molecular Ecology Resources 8: 103106. doi:10.1111/j.1471-8286.2007.01931.x.

Sebastiani F, Pinzauti F, Kujala ST, González-Martínez SC \& Vendramin GG (2012) Novel polymorphic nuclear microsatellite markers for Pinus sylvestris L. Conservation Genetics Resources 4: 231-234. doi:10.1007/s12686-011-9513-5.

Soranzo N, Provan J \& Powell W (1998) Characterization of microsatellite loci in Pinus sylvestris L. Molecular Ecology 7: 1260-1261.

Vendramin GG, Lelli L, Rossi P \& Morgante M (1996) A set of primers for the amplification of 20 chloroplast microsatellites in Pinaceae. Molecular Ecology 5: 595-598. doi:10.1111/j.1365294X.1996.tb00353.x.

Wachowiak W, Cavers S \& Żukowska WB (2015) Interspecific gene flow and ecological selection in a pine (Pinus sp.) contact zone. Plant Systematics and Evolution 301: 1643-1652. doi:10.1007/ s00606-014-1182-x.

Wachowiak W, Żukowska WB, Wójkiewicz B, Cavers S, Litkowiec M (2016) Hybridization in contact zone between temperate European pine species. Tree Genetics \& Genomes 12: 48. doi:10.1007/ s11295-016-1007-x.

Willyard A, Syring J, Gernandt DS, Liston A \& Cronn R (2007) Fossil calibration of molecular divergence infers a moderate mutation rate and recent radiations for Pinus. Molecular Biology and Evolution 24: 90-101. doi:10.1093/molbev/msl131.

Wójkiewicz B \& Wachowiak W (2016) Substructuring of Scots pine in Europe based on polymorphism at chloroplast microsatellite loci. Flora - Morphology, Distribution, Functional Ecology of Plants 220: 142-149. doi:10.1016/j. flora.2016.03.005.

Zhou Y, Bui T, Auckland LD \& Williams CG (2002) Undermethylated DNA as a source of microsatellites from a conifer genome. Genome 45: 91-99. doi:10.1139/g01-119. 